\section{PENGARUH ANTI OKSIDAN PHENYL BETA NAPHTYLAMINE (PBN), DAN VARIASI RSS DENGAN SBR TERHADAP SIFAT FISIKA KOMPON TALANG KARET}

Oleh : Siti Rochani dan Asrilah

\section{ABSTRACT}

The aim of the research was to find some important characteristics of rubber gutter compound such as The aim of the research wasto lensile strength, elongation at break, and constant defroction mixing of natural (RSS) and sinthetic Naphtylamine on it. Rubber gutter compound was made from mixing of natural (RSS) and sinthetic Naphrylamine. Mercapto Benz Thiazol Disulfide, Diphenyl Guanidine and Sulphur. Three composia 40 , and $1: 1,5 ; 2$ respectively. A stastistical prosedure was used to analyze the data of the physical 40, and $1: 1,5: 2$ respectively. A stastistical prosedure was used to analyze compared to the physical strength characteristic of rubber gutter compound produced. The results were compared to the physical strength of rubber gutter available in the market. From the statistical analyses they denoted that the levels of Phenyl Beta Naphtylamine gave significant effects on cosition levels of RSS/SBR could produce however there was no effect on ten compounds which were signficant difference in the tempounds resulted from this reseach had better tensile strength and elongation compared to rubber gutter available in the market

\section{INTISARI}

Penelitian ini bertujuan untuk mendapatkan karakteristik kompon talang karet terutama sifat sifat penting seperti tegangan putus, perpanjangan putus dan pampat tetap, karena penambahan anti oksidan Phenyl Beta Naphtylamine. Kompon talang karet dibuat dari campuran karet alam (RSS) dan karet sintetis (SBR) dengan penambahan bahan pembantu yaitu Zink Oksida, Asam Stearat, Naphtenic Oil, HAF black, Phenyl Beta Naphtylamine, Mercapto Benz Thiazol Disulphyte, Diphenyl Guanidine dan HAF black, Phenyl Beta Naphlylamine, Mercapto Benz Thazal Campuran RSS dengan SBR di variasi dengan perbandingan 40/60; 50/50; dan 60/40, sedang Sulfur. Campuran RSS dengan SBR di variasi dengan perbandingan 40/60; $50 / 50$; dan 60/40. sedang Phenyl Beta Naphtylamine yang ditambahkan adalah $1,1,5$, dan 2 bagian. Kompon yang didapalkan, setelah diuj, hari asaran. Dari hasil analisa statistikvariasi Phenyl Beta Naphtylamine berpengaruh lalang kar sifat tegangan putus tidak nyata pada sifat perpanjangan putus dan pampat tetap, sedangkan pada sifal tegangan pus tidak berbeda nyata. Variasi pencampuran RSS dengan SBR memberikan perbedaan yang nyata pada sijat fisis tegangan putus, perpanjangan putus dan pampat tetap. Dibandingkan dengan beberapa contoh yang diambil dari pasaran, kompon hasil penelitian mempunyai tegangan putus dan perpanjangan putus yang lebih baik.

\section{PENDAHULUAN}

Dalam pembuatan barang karet, proses pengomponan dilakukan dengan mencampur bahan baku karet dan bahan bahan pembantu lain di dalam open mill atau banbury mixer. Pada proses penggilingan ini, karet mengalami pelunakan karena ieiputusnya rantai-rantai molekul karet. Proses pelunakan ini dipercepat lagi ddengan adanya panas yang timbul karena gesekan antar molekul karet dan antara karet dengan rol open mill atau bambury mixer. Pemendekan rantai molekul karet dapat ierjadi dan meningkat dengan cepat, menyebabkan karet dapat terjadi dan meningkat dengan cepat, menyebabkan karet semakin lunak dan kemungkinan dapat mengalami vulkanisasi awal. Kondisi seperti tersebut diatas menentukan sifat hompon yang dihasilkan, dan dengan demikian juga menentukan sifat fisis barang faret yang dihasilkan dari proses pencampuran tersebut, terutama apabila digunakan hahan pengisi karbon hitam, Untuk mendapatkan hasil pencampuran yang baik umumnya penambahan bahan pembantu di bagi dalam dua tahap.

Tahap pertama di masukkan bahan pengisi, pelunak minyak serta bahanbahan yang tidak akan menyebabkan terjadinya vulkanisasi. Pencampuran ini dilakukan sampai semua pengisi tersebut tersebar secara merata kedalam karet. Pada tahap kedua proses pencampuran ditambahkan bahan-bahan yang ada hubungannya dengan proses vulkanisasi seperti bahan pencepat vulkanisasi dan bahan pemvulkanisasi.

Bahan pembantu yang berfungsi sebagai anti oksidan ditambahkan untuk mencegah terjadinya kerusakan karet yang disebabkan oksidasi karet karena adanya pengaruh sinar matahari. Pemilihan anti oksidan harus mempertimbangkan beberapa faktor seperti mudah bercampur dengan karet, tidak mempengaruhi vulkanisasi, lidak menyebabkan perubahan warna kompon karet, serta tidak beracun.

Semua barang karet dapat terdegredasi, yang ditandai dengan lengket lengket, lunak kemudian mengeras dan sobek. Kerusakan ini dinamakan aging, yaitu lerjadinya aksidasi karet karena pengaruh sinar matahari. Disamping itu ozon juga dapat menyebabkan kerusakan. Untuk dapat mencegah terjadinya aging, dalam pembuatan kompon karet perlu ditambahkan zat anti oksidan.

Beberapa anti oksidan yang penting adalah sebagai berikut,

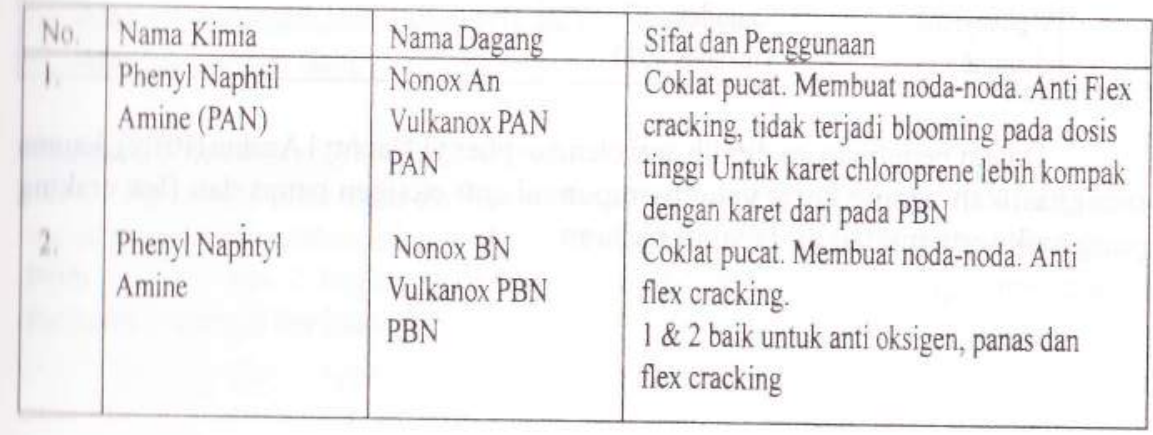

Vol. XII No. 25 Th. $1997 / 1998$ 


\begin{tabular}{|c|c|c|c|}
\hline 3. & $\begin{array}{l}\text { Aceton Anylin } \\
\text { Condensasi }\end{array}$ & \multirow{2}{*}{$\begin{array}{l}\text { Santoflex AW } \\
\text { Santoflex DD } \\
\text { Santoflex R } \\
\text { Nonox B } \\
\text { Nonox BL } \\
\text { Santoflex DPA } \\
\text { Nonox OD }\end{array}$} & \multirow{3}{*}{$\begin{array}{l}\text { Coklat sangat pucat, coklat gelap, anti } \\
\text { oksidan bagus, anti panas sangat bagus } \\
\text { flex cracking kurang bagus. } \\
\text { Coklat muda pucat atau coklat tua. anti } \\
\text { oksidan bagus, anti panas sangat bagus } \\
\text { anti ozon tidak berpengaruh. } \\
\text { Coklat pucat. Efek pencegahan degradasi } \\
\text { karena oksidasi, panas \& flexing bagus. } \\
\text { Terhadap ozon tidak punya efek pencegahan. } \\
\text { Terhadap metal sedikit punya efek pencegahan. }\end{array}$} \\
\hline 4. & $\begin{array}{l}\text { Aceton diphenyl } \\
\text { Amine Condensasi }\end{array}$ & & \\
\hline 5. & $\begin{array}{l}\text { Alkyl (C-C) ated } \\
\text { diphenyl Amine }\end{array}$ & Nonox OD & \\
\hline 6. & $\begin{array}{l}\text { Alkoxy (- } \mathrm{CH} 30) \\
\text { diphenyl Amine }\end{array}$ & & $\begin{array}{l}\text { Efek pencegahan } \\
\text { - panas cukup } \\
\text { - oksigen bagus } \\
\text { - fpixing sangat bagus } \\
\text { - metal kurang } \\
\text { - ozon tidak ada. }\end{array}$ \\
\hline 7. & $\begin{array}{l}\text { NN' diphenyl P } \\
\text { Phenulene } \\
\text { diamine }\end{array}$ & $\begin{array}{l}\text { DPPD } \\
\text { Nonox DPPD }\end{array}$ & $\begin{array}{l}\text { Jarang dipakai karena kurang kompok } \\
\text { dengan karet. Biasa dipakai dalam blending } \\
\text { dengan Nonox HFN dan Santeflek } 75 \text {. } \\
\text { Pencegahan oksidasi panas flexing bagus. } \\
\text { Pencegahan mental ctalys sedikit. Pence- } \\
\text { gahan ozon cukup. }\end{array}$ \\
\hline 8. & $\begin{array}{l}\text { NN' dinaphtyl } \\
\text { phenylene }\end{array}$ & $\begin{array}{l}\text { Nonox CI } \\
\text { Santowhite CI }\end{array}$ & $\begin{array}{l}\text { Efisiensi pencegahan degradasi : } \\
\text { - Oksigen bagus } \\
\text { - metal catalys sangat bagus } \\
\text { - ozon tidak ada }\end{array}$ \\
\hline 9. & $\begin{array}{l}\mathrm{N} \text { phenyl N'alkyl } \\
\text { P phenylene } \\
\text { diamine }\end{array}$ & $\begin{array}{l}\text { Nonox ZA } \\
\text { Sanflex I P } \\
\text { Santoflex B }\end{array}$ & Efisiensi pencegahan degradasi bagus \\
\hline 10. & $\begin{array}{l}\text { NN' dialkyl } \\
\text { P phenylene } \\
\text { diamine }\end{array}$ & $\begin{array}{l}\text { Santoflek } 77 \\
\text { Santoflex } 217 \\
\text { Vulkanox } 4030\end{array}$ & Efisiensi pencegahan bagus Bersifat racun \\
\hline
\end{tabular}

Dalam penelitian ini dipilih anti oksidan phenyl Naphtyl Amine (PBN), karena menghasilkan barang karet yang mempunyai anti oksigen panas dan flex craking yang baik serta mudah di dapat di pasaran.

\section{MATERI DAN METHODA PENELITIAN}

\section{Materi Penelitian}

Materi yang digunakan dalam penelitian ini adalah :

Bahan-bahan Penelitian

Bahan baku :

Kater alam (Rubber smoked sheet)

Karet sintetik (Styrene Butadiene Rubber)

Bahan pembantu

Bahan Pelunak : Naphthenic oil

Bahan Penggiat : $\mathrm{Zn} \mathrm{O}$, asam stearat

Bahan pengisi : HAF Black

Bahan oksidan : PBN

Bahan pencepat : DPG, MBTS

Zat pemvulkanisasi : Sulphur

Alat-alat penelitian

Peralatan pembuatan Kompon

- Timbangan

Pisau

Krus porselin

Cetakan slab

Hydraulic press

Two roll mill

Stop watch

Curo meter

Alumunium foil

Peralatan pengujian terdiri dari

Alat uji waktu optimum kemasakan karet (cure time)

Alat uji tegangan putus dan perpanjangan putus

Alat uji pampat tetap

\section{Methode Penelitian}

Penelitian dilakukan dengan memvariasikan RSS/SBR dan PBN. Variabelvariabel yang dikerjakan adalah : RSS/SBR; $40 / 60 ; 50 / 50$ dan 80/40 bagian dengan $P B N: 1 ; 1,5$ dan 2 bagian, sehingga diperoleh 9 kompon talang karet dengan formulasi sebagai berikut : 
Tabel 1. Formulasi kompon talang karet :

\begin{tabular}{|l|l|c|c|c|c|c|c|c|c|c|}
\hline \multirow{2}{*}{ No. } & Bahan & \multicolumn{10}{|c|}{ KOMPON } \\
\cline { 2 - 10 } & & 1 & 2 & 3 & 4 & 5 & 6 & 7 & 8 & 9 \\
\hline 1. & RSS & 40 & 40 & 40 & 50 & 50 & 50 & 60 & 60 & 60 \\
2. & SBR 1502 & 60 & 60 & 60 & 50 & 50 & 50 & 40 & 40 & 40 \\
3. & ZnO & 5 & 5 & 5 & 5 & 5 & 5 & 5 & 5 & 5 \\
4. & Asam stearet & 1,5 & 1,5 & 1,5 & 1,5 & 1,5 & 1,5 & 1,5 & 1,5 & 1,5 \\
5. & Naph oil & 5 & 5 & 5 & 5 & 5 & 5 & 5 & 5 & 5 \\
6. & HAF black & 45 & 45 & 45 & 45 & 45 & 45 & 45 & 45 & 45 \\
7. & PBN & 1 & 1,5 & 2 & 1 & 1,5 & 2 & 1 & 1,5 & 2 \\
8. & MBTS & 1,2 & 1,2 & 1,2 & 1,2 & 1,2 & 1,2 & 1,2 & 1,2 & 1,2 \\
9. & DPG & 0,4 & 0,4 & 0,4 & 0,4 & 0,4 & 0,4 & 0,4 & 0,4 & 0,4 \\
10. & Sulphur & 2,5 & 2,5 & 2,5 & 2,5 & 2,5 & 2,5 & 2,5 & 2,5 & 2,5 \\
\hline
\end{tabular}

Data-data hasil penelitian dihitung secara statistik menggunakan rancangan faktorial

\section{Pembuatan kompon}

Proses pembuatan kompon talang karet adalah sebagai berikut :

- Bahan-bahan ditimbang sesuai dengan formulasi pada tabel 1 menggunakan timbangan analitis

- Selanjutnya bahan yang sudah ditimbang digiling dengan alat two roll mill.

- Mula-mula karet alam (RSS) dimastikasi (digiling) sampai plastis

- Tambahkan SBR 1502 (karet sintetis), giling sampai plastis

- Suhu gilingan tidak boleh lebih dari $70 \mathrm{C}$

- Setelah plastis, tambahkan secara berurutan, $\mathrm{Zn} \mathrm{O}$, asam stearat, giling sampai homogen.

- Tambahkan Naphtenic oil dan carbon black

- Tambahkan PBN, MBTS dan DPG setiap kali penambahan bahan giling sampai homogen.

- Terakhir tambahkan sulphur dan giling hingga homogen

- Setelah kompon jadi simpan dalam ruang kondisi selama \pm 24 jam.

- Kemudian lakukan uji cure time untuk mengetahui waktu optimum kemasakan karet

Vulkanisasikan kompon dalam bentuk slab, dengan alat hidraulik pres pada suhu $150 \mathrm{C}$, tekanan $150 \mathrm{Kg} / \mathrm{Cm}$ dan waktu sesuai hasil uji, kemasakan karet.

\section{Nembuatan slab}

Letakan kompon pada cetakan kemudian tutup dengan plat yang sebelumnya andah diberi Aluminium Foil atau dibasahi dengan minyak Silikon.

Masukkan dalam hidraulic press yang sebelumnya sudah dipanaskan pada whiu $150 \mathrm{C}$ dengan tekanan $150 \mathrm{~kg} / \mathrm{cm}$ dan waktu sesuai hasil uji kemasakan karet. Neielah waktu tercapai hentikan pemanasan dan keluarkan cetakan dari hyraulic press, kemudian setelah dingin keluarkan kompon dari cetakan. Sebelum dibuat contoh uji kondisikan selama 24 jam dalam ruang kondisi.

\section{Pengujian}

Untuk mengetahui sifat-sifat fisis kompon talang karet perlu dilakukan pengujian-pengujian kompon hasil penelitian yaitu : Tegangan putus, perpanjangan puitus, dan pampat tetap. Ketiga uji tersebut diatas dilakukan karena sifat tegangan putus, perpanjangan putus dan pampat tetap sangat menentukan sifat barang jadi karet

Prosedur pelaksanaan cara uji adalah sebagai berikut

Tegangan putus dan perpanjangan putus

Pengujian dilakukan dengan alat uji ketahanan tarik. Potong cuplikan uji dalam lentuk dayung (lihat gambar dibawah ini) memakai pisau pons. Beri tanda dua garis sejajar pada cuplikan berjarak $2 \mathrm{~cm}$ simetris ditengah-tengah dayung. Ukur lebar dan tebal cuplikan kemudian pasang pada alat sehingga jarak antara kedua lepitan $50 \mathrm{~mm}$. Penarikan dikerjakan dengan kecepatan $25+-1 \mathrm{~cm} /$ menit sampai cuplikan putus.

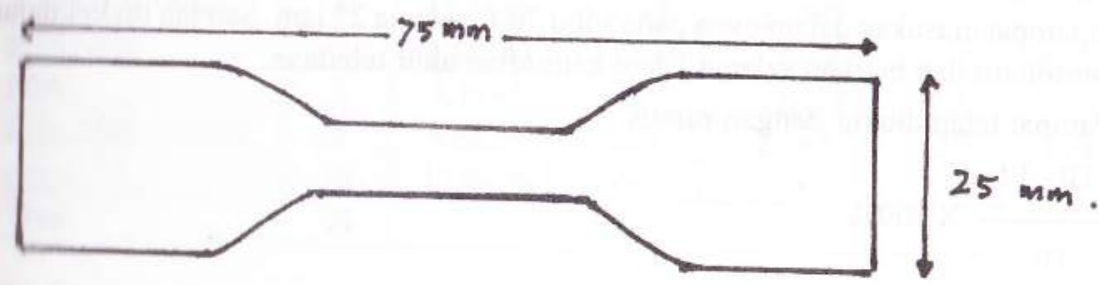

Gambar : Cuplikan contoh uji tegangan putus dan perpanjangan putus.

Vol. XII No. 25 Th. 1997/1998 


\section{Perhitungan}

Tegangan putus $-\frac{F}{\mathrm{t} x \mathrm{w}}$
$\mathrm{L} 1$ - Lo

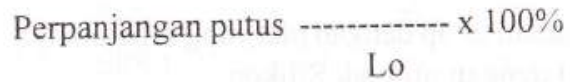

\section{Keterangan :}

$\mathrm{F}$ = beban yang diperlukan untuk menarik cuplikan sampai putus, $\mathrm{kg}$.

$\mathrm{t}=$ tebal cuplikan, $\mathrm{cm}$

$\mathrm{w}=$ lebar cuplikan, $\mathrm{cm}$

Lo = panjang mula-mula cuplikan antara 2 tanda garis

Ll = panjang cuplikan antara 2 garis, pada waktu putus

\section{Pampat tetap}

Tujuan untuk menentukan perubahan tebal suatu contoh karet bila ditekan selama beberapa waktu. Pengujian ini perlu untuk barang karet yang sering mengalami penekanan.

\section{Contoh uji berbentuk}

Silinder, ukuran diameter $30 \mathrm{~mm}$, tinggi $15 \mathrm{~mm}$.

Ukur tebal dan kekerasan contoh uji, kemudian letakan diantara dua plat. Kencangkan baut sampai contoh terpampat. Besarnya pampat tergantung pada kekerasannya.

Untuk kekerasan 45-64 shore A besarnya pampat 30\% dari tebal semula.

Untuk kekerasan 65-84 shore A besarnya pampat 25\% dari tebal semula. Setelah dipampat masukan dalam oven pada suhu $70^{\prime} \mathrm{C}$ selama $22 \mathrm{jam}$. Setelah itu kekuatan contoh uji dan biarkan selama 1 jam kemudian ukur tebalnya.

Pampat tetap diukur dengan rumus $=$

$$
\text { T0 - T1 } \times 100 \%
$$$$
\text { T0 }
$$

\section{dimana :}

$\mathrm{TO}=$ tebal sebelum dipampat

$\mathrm{Tl}=$ tebal setelah dipampat (1 jam setelah dilepas)

\section{IIASIL - HASIL PENELITIAN DAN PEMBAHASAN}

IIasil penelitian

Hasil penelitian berupa data hasil uji sifat fisis kompon talang karet yang meliputi uji tegangan putus, perpanjangan putus, pampat total

Ilasil uil tegangan putus

\begin{tabular}{|c|c|c|c|c|c|c|}
\hline \multirow[t]{2}{*}{ KSS/SBR } & \multirow[t]{2}{*}{ PBN } & \multicolumn{3}{|c|}{ Ulangan } & \multirow[t]{2}{*}{ Total } & \multirow[t]{2}{*}{ Rata-rata } \\
\hline & & 1 & 2 & 3 & & \\
\hline \multirow[t]{3}{*}{$40 / 60$} & 1 & 9,07 & 8,98 & 10,91 & 28,96 & 9,65 \\
\hline & 1,5 & 10,30 & 12,22 & 10,09 & 32,61 & 10,87 \\
\hline & 2 & 8,8 & 10,74 & 10,05 & 29,60 & 9,87 \\
\hline \multirow[t]{3}{*}{$50 / 50$} & 1 & 7,65 & 10,12 & 11,52 & 29,29 & 9,76 \\
\hline & 1,5 & 10,99 & 9,67 & 10,90 & 31,56 & 10,52 \\
\hline & 2 & 10,14 & 10,10 & 10,08 & 30,32 & 10,11 \\
\hline \multirow[t]{3}{*}{$60 / 40$} & 1 & 10,13 & 11,73 & 13,69 & 35,55 & 11,85 \\
\hline & 1,5 & 10,17 & 12,93 & 11.19 & 34,29 & 11,43 \\
\hline & 2 & 13,11 & 13,50 & 14,74 & 41,35 & 13,78 \\
\hline \multicolumn{2}{|l|}{ Total } & 90,37 & 99,99 & 103,17 & 293,53 & \\
\hline
\end{tabular}

Tabel 2 : Data hasil uji tegangan putus $(\mathrm{N} / \mathrm{mm} 2)$

Dari data hasil uji tegangan putus, setelah dihitung secara statistik didapatkan analisa lidik ragam sebagai berikut :

Tabel 3. Anaisa sidik ragam untuk uji tegangan putus

\begin{tabular}{|l|c|c|c|c|c|c|} 
Sumber Variasi & Db & Jk & Rjk & F hitung & \multicolumn{2}{|c|}{ F tabel } \\
\cline { 5 - 7 } Ulangan & & & & & $5 \%$ & $1 \%$ \\
lieat Kombinasi & 2 & 9,8703 & 4,9351 & 5,0353 & & \\
RSS/SBR & 2 & 42,5351 & 5,3168 & 5,4247 & & \\
IIIN & 29,6889 & 14,8444 & $15,1458^{* *}$ & 3,55 & 6,01 \\
ISSS/SBR X PBN & 4 & 3,1635 & 1,5817 & 1,6138 & 3,55 & 6,01 \\
I ror & 9,6827 & 2,4206 & 2,4697 & 2,93 & 4,58 \\
Iotal & 26 & 17,6426 & 0,9801 & & & \\
\hline
\end{tabular}

lika F hitung dibandingkan dengan tabel, terlihat bahwa variasi RSS/SBR berbeda angat nyata, sedangkan PBN tidak berpengaruh terhadap sifat tegangan putus.

Vol. XII No. 25 Th. $1997 / 1998$ 
Hasil uji perpanjangan putus

Tabel 4 : Data hasil uji perpanjangan putus ( \%)

\begin{tabular}{|l|c|c|c|c|c|c|}
\hline \multirow{2}{*}{ RSS/SBR } & \multirow{2}{*}{ P B N } & \multicolumn{3}{|c|}{ Ulangan } & \multirow{2}{*}{ Total } & \multirow{2}{*}{ Rata-rata } \\
\cline { 3 - 5 } & & 1 & 2 & 3 & & \\
\hline $40 / 60$ & 1 & 200 & 185 & 210 & 595 & 193,33 \\
& 1,5 & 200 & 235 & 200 & 635 & 211,66 \\
& 2 & 160 & 205 & 185 & 550 & 183,33 \\
$50 / 50$ & 1 & 150 & 190 & 210 & 550 & 183,33 \\
& 1,5 & 200 & 175 & 195 & 570 & 190,00 \\
& 2 & 190 & 180 & 180 & 550 & 183,33 \\
$60 / 40$ & 1 & 195 & 225 & 230 & 650 & 216,67 \\
& 1,5 & 200 & 235 & 230 & 665 & 221,67 \\
& 2 & 250 & 275 & 325 & 850 & 283,33 \\
\hline Total & & 1745 & 1905 & 1965 & 5615 & \\
\hline
\end{tabular}

Dari data hasil uji perpanjangan putus tersebut diatas kemudian telah dihitung secara statistik didapatkan analisa sidik ragam sebagai berikut

Tabel 5. Analisa sidik ragam untuk uji perpanjangan putus

\begin{tabular}{|l|c|c|c|c|c|c|}
\hline Sumber Variasi & Db & Jk & Rjk & Fhitung & \multicolumn{2}{|c|}{ F tabel } \\
\cline { 6 - 8 } & & & & & $5 \%$ & $1 \%$ \\
\hline Ulangan & 2 & 2874,07 & 1437,03 & 4,37 & & \\
Treat Kombinasi & 8 & 24579,62 & 3072,45 & 9,35 & & \\
RSS/SBR & 2 & 15012,96 & 7506,48 & $22,48^{* *}$ & 3,55 & 6,01 \\
P BN & 2 & 1335,18 & 667,59 & 2,03 & 3,55 & 6,01 \\
RSS/SBR X PBN & 4 & 8234,25 & 2057,87 & $6,26^{* *}$ & 2,93 & 4,58 \\
Error & 18 & 5909,25 & 328,29 & & & \\
\hline Total & 26 & & & & & \\
\hline
\end{tabular}

Variasi RSS/SBR dan interaksi RSS/SBR dengan PBN mempunyai F hitung yang lebih besar dari pada $\mathrm{F}$ tabel pada tingkat kepercayaan $99 \%$ yang berarti variasi RSS/SBR dan interaksi RSS/SBR dengan PBN menghasilkan perpanjangan putus yang berbeda sangat nyata.
IIasil uji Pampat tetap (\%)

Tabel 6: Data hasil uji pampat tetap

\begin{tabular}{|l|c|c|c|c|c|c|}
\hline \multirow{3}{*}{ RSS/SBR } & P B N & \multicolumn{3}{|c|}{ Ulangan } & Total & \multirow{2}{*}{ Rata-rata } \\
\cline { 2 - 5 } 400 & 1 & 1 & 2 & 3 & & \\
& 1,5 & 14,40 & 9,66 & 10,33 & 29,39 & 9,79 \\
& 2 & 12,68 & 15,45 & 13,69 & 44,09 & 14,69 \\
$50 / 50$ & 1 & 15,15 & 10,15 & 14,07 & 39,37 & 13,12 \\
& 1,5 & 18,87 & 16,53 & 14,20 & 49,60 & 16,53 \\
& 2 & 12,67 & 13,91 & 14,73 & 41,31 & 13,77 \\
$60 / 40$ & 1 & 5,95 & 13,79 & 12,85 & 32,59 & 10,86 \\
& 1,5 & 14,24 & 13,90 & 11,13 & 39,27 & 13,09 \\
& 2 & 13,65 & 12,53 & 10,86 & 37,04 & 12,34 \\
\hline 101 a 1: & & 117,56 & 116,47 & 112,11 & 346,14 & \\
\hline
\end{tabular}

Data tersebut diatas setelah dihitung secara statistik menghasilkan analisa sidik ragam iebagai berikut :

Tabel 7. Analisa sidik ragam untuk uji pampat tetap

\begin{tabular}{|l|c|c|c|c|c|c|} 
Sumber Variasi & $\mathrm{Db}$ & $\mathrm{Jk}$ & $\mathrm{Rjk}$ & $\mathrm{F}$ hitung & \multicolumn{2}{|c|}{$\mathrm{F}$ tabel } \\
\cline { 5 - 7 } & & & & & $5 \%$ & $1 \%$ \\
\hline Ulangan & 2 & 1,85 & 0,92 & 0,21 & & \\
Ireat Kombinasi & 8 & 102,97 & 12,87 & 3,01 & & \\
IRSS/SBR & 2 & 37,21 & 18,60 & $4,35 *$ & 3,55 & 6,01 \\
PB N & 2 & 57,61 & 28,80 & $6,74 * *$ & 3,55 & 6,01 \\
KSS/SBR X PBN & 4 & 8,15 & 2,03 & 0,47 & 2,93 & 4,58 \\
Iror & 18 & 76,97 & 4,27 & & & \\
Iotal & 26 & & & & & \\
\hline
\end{tabular}

Variasi RSS/SBR, maupun variasi PBN berpengaruh nyata terhadap nilai hasil uji равараt tetap.

\section{VIMAHASAN}

A Variasi perbandingan RSS/SBR berpengaruh sangat nyata terhadap hasil uji legangan putus, sedangkan faktor PBN serta interaksi antara RSS/SBR dengan 
PBN tidak menunjukan parbedaan yang nyata.

Dengan menggunakan perbedaab terkecl (Least Significant Difference), yang mempunyai nilai 0,98 maka variasi RSS/SBR 40/60 mempunyai tegangan putus yang tidak berbeda nyata dengan variasi RSS/SBR 50/50. Sedangkan variasi RSS/SBR 60/40 berbeda nyata dengan yang lain dan memberikan nilai paling tinggi (12,35 N/mm2). Hal ini disebabkan karena karet alam (RSS) mempunyai sifat tegangan putus yang lebih baik dibandingkan dengan karet sinthets (SBR). Sehingga makin banyak jumlah karet alam maka sifat tegangan putusnya semakn tinggi.

b. Perpanjangan putus sangat dipengaruhi oleh faktor RSS/SBR, tetapi tidak dipengaruhi oleh variasi PBN. Hasil perhitungan LSD (5\%) didapatkan nilai 17,93, sehingga variasi RSS/SBR 40/60 dan RSS/SBR 50/50 mempunyai perpanjangan putus yang tidak berbeda nyata. Sedangkan dengan RSS/SBR $60 / 40$ mempunyai perpanjangan putus yang berbeda nyata dan menunjukan nilai paling tinggi $(240,55 \%)$. Hal ini disebabkan karena sifat karet alam mempunyai sifat perpanjangan putus yang lebih baik dibanding dengan karet sinthetis. Sehingga makin banyak karet alam maka perpanjangan putusnya semakin tinggi. Interaksi antara RSS/SBR dengan PBN juga menunjukan perbedaan yang nyata. Dengan menghitung perbedaan terkecil didapatkan bahwa variasi interaksi antara RSS/SBR 60/40 dengan PBN 2 bagian mempunyai perpanjangan putus tertinggi $(283,33 \%)$ dan berbeda nyata dengan variasi yang lain.

c. Tabel analisa sidik ragam untuk pampat tetap menunjukkan bahwa baik variasi RSS/SBR maupun variasi Phenyl Beta Naphtylamine berpengaruh nyata terhadap sifat pampat tetap, sedangkan interaksinya tidak. Pada variasi RSS/ SBR setelah dihitung dengan nilai LSD 5\% didapatkan bahwa variasi RSS/SBR 40/60 tidak berbeda nyata dengan RSS/SBR 60/40, tetapi berbeda nyata dengan RSS/SBR 50/50. Berbeda dengan tegangan putus dan perpanjangan putus, nilai pampat tetap yang terbaik adalah yang nilainya terendah, sehingga variasi RSS/ SBR yang terbaik adalah $40 / 60$, sedangkan variasi PBN yang terbaik adalah 1 bagian.

\section{KESIMPULAN}

Dari hasil penelitian dapat disimpulkan sebagai berikut :

1. Variasi perbandingan RSS/SBR sangat berpengaruh terhadap sifat tegangan putus, perpanjangan putus dan pampat tetap, sedangkan variasi PBN tidak berpengaruh terhadap tegangan putus, namun berpengaruh terhadap sifat pampat tetap, dan interaksi antara RSS/SBR dengan PBN berpengaruh terhadap sifat คетраnjangan putus.

1 Hemakin tinggi perbandingan RSS/SBR maka sifat tegangan putus dan 1еipanjangan putusnya semakin baik. Kompon dengan variasi perbandingan 11:S/SBR 60/40 mempunyai nilai tegangan putus tertinggi ( $12,35 \mathrm{~N} / \mathrm{mm} 2)$ dan nilai perpanjangan putus tertinggi ( $240,55 \%)$.

1. bibundingkan dengan talang karet yang dambil dari pasaran (4 macam), kompon falang karet hasil penelitian mempunyai tegangan putus dan perpanjangan putus yang lebih baik (talang karet dari pasaran mempunyai nilai rata-rata tegangan putus $8,04 \mathrm{~N} / \mathrm{mm} 2$ dan perpanjangan putus $54,99 \%$ ).

1 Nilai pampat tetap yang terbaik adalah kompon dengan variasi RSS/SBR 40/60 $(11,88 \%)$, sedangkan pada variasi PBN, nilai pampat tetap yang terbaik adalah PIIN I bagian $(11,256 \%)$.

\section{DAITAR PUSTAKA}

If M Blow, BSc., PhD., C. Chem, FRSC., FPRI and C. Hepburn, BSc., ANCRT., C. Chem, FRSC., FPRI.; Rubber Technology and Manufacture, Second Idition, Butterworth Scientific, London.

1 IIarry Baron ; Modern Rubber Chemistry. D. Van Nostrad Company Inc. New York USA

I Midha Arizal, DR. ; Rubber Processing Oil Product Dalam Negeri. Seminar Rubber Processing Oil, Semarang.

I SIIP Board of Consultants and Engineer; Rubber Technology and Manufacture, Small Business Publication, SBP Building 4/45, Roop Nagar, New Delhi 110007.

1. Wemer Hoffman; Rubber Technology Handbook. Hanser Publishers, Munich, New York, 1989. 